\title{
The Effects of Group Guidance Peer Mentoring Module on Grade Performance of Low Academic Achievement Students in a Higher Education Institution
}

\author{
Haizan binti Mohd Taha, Mastura binti Johar and Mardian Shah bin Omar \\ Universiti Tenaga Nasional (UNITEN), Malaysia \\ Haizan@uniten.edu.my
}

\begin{abstract}
This study is to evaluate the effects of group guidance on academic mentoring group intervention among foundation students in Private Higher Education Institutions (PHEIs). Whereas, the objective is to measure the effects of peer mentor group guidance on a group of mentor trained under Peer Mentoring Module for academic achievement of students in the Foundation Engineering Program. A total of forty subjects (mentee) have undergone academic mentoring program with forty trained peer mentors, and subjects are low academic achievement of Engineering Foundation Program students in Universiti Tenaga Nasional (UNITEN) who obtained a Cumulative Grade Point Average (CGPA) below 2:00 points, failed subject Calculus 1 (MATF 115) and did not engage in any other mentoring program. Subjects were grouped in 2 groups; Control and Treatment group for a period of 10 weeks by using control studies, the tests before and after (pre and post-test). Component of grade performance is based on achieving results for Calculus 1. Apart from descriptive statistical analysis, nonparametric test are applied to determine its effectiveness in increasing the average difference for the group. Results showed that subjects in the intervention group experienced a positive improvement over the objectives of the study. Interestingly, treatment group showed a significant difference in performance grade for Calculus 1 with a difference of $(M=54.5500, S D=8.1336)$ with the impact strength of $12 \%$. In summary, the intervention of group guidance on Peer Mentoring Module have contributed positively to the findings of the grade performance of students with low academic achievement who have successfully completed their studies in Private Higher Education Institutions and Public Higher Education Institutions in general.
\end{abstract}

Keywords: Group guidance, peer mentoring module, grade performance, academic achievement and higher education institutions

\section{Introduction}

Studies in Private Higher Education Institutions (PHEIs) for university levels include programs like Foundation, Diploma, Degree and Graduate Studies. Foundation programs are important because successful students at this level will be determined to the next level and emblem the quality for the institutions. Moreover, the number of students increased for Degree programs will make the institutions more quality and will be recognized as world class university. For students to reach self-development with high achievement, a few programs such as guidance and mentoring should be implemented in higher learning institutions. The mentoring process catogerized by friendly and ethical relationship between protege and experienced mentor, capable to show positive role towards mentee's positive develpoment. Anderson and Shannon (1988) defined mentoring as a nurturing process in which a more skilled and a more experienced person, serving as a role model, teaches, sponsors, encourages, counsels and befriends a less skilled or a less experienced person for the purpose of promoting the latter's personal and/or personal development. Mentoring functions are carried out within the context of an ongoing, caring relationship between the mentor and associate. The real strength of mentoring comes from the social relationship based connections, focused towards desired outcomes, meeting the needs of both the mentor and protégé (mentee). Mentoring relationship between peers can be based on trust and empathy.

In Model of Youth Mentoring by DuBois and Karcher (2005), it shows that this kind of special relationship on trust and empathy will lead to social-emotional, identity, and cognitive development. This model assumed that positive result can be achieved through grade performance, emotional stability and good behavior. Therefore, the Peer Mentoring Module (PMM) is developed to train future peer mentors with soft skills that will make them more confidence, more caring and make them realize that the more knowledge they share, the more knowledge they will gain. The PMM is built systematically and provides skills namely; interpersonal relationship, communication, motivation, empathy and emotional stability for peer mentors to give opinions and constructive responses within group cohesiveness. As a result, the 
existence of mentoring relationship will be very strong among them and their protégé. Figure 1 below refers the PMM which is based from the Model of Youth Mentoring by DuBois and Karcher (2005).

Figure 1: Peer Mentor Module based on the Model of Youth Mentoring
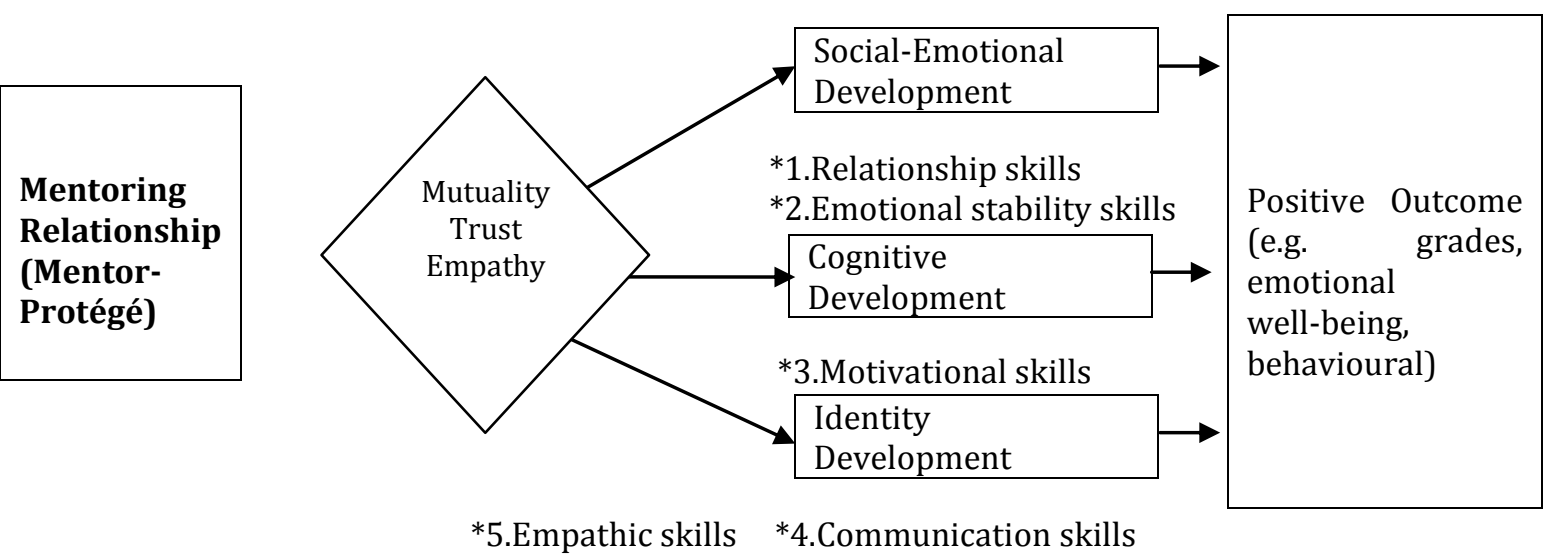

*Five Skills in Peer Mentoring Module (PMM)

Sources: Model of Youth Mentoring: DuBois \& Karcher. (2005). Handbook of Youth Mentoring: Sage Publication, Inc. California, USA, (3), 30-38.

The Peer Mentoring Module (PMM) is also developed with various soft skills related to Big Five Personality Dimensions consists of agreeableness, conscientiousness, extraversion, openness and neuroticism by Oliver and Sanjay (1999) along with Person Centered Theory including aspects of unconditional positive regard, self actualization, active listening, empathy and genuine by Rogers (1959). In addition, Kolb Model of Experiential Learning by Wolf and Kolb (1984) is used to relate the activities regarding the PMM with types of experience faced by both mentor and protégé (mentee) during their weekly academic mentoring sessions.

\section{Methodology}

Validity of content has been tested towards the Peer Mentoring Module (PMM) on statements or items regarding activities from the module in paper presented at UPSI-UPI conference at Shah Alam, Malaysia by Haizan and Fauziah (2012). The outcome shows that maximum coefficient value of content validity made by 5 experts from local universities is 0.87 (87\%) and total coefficient validity is $0.84(84 \%)$. Therefore, a study has been carried out to look at the effectiveness of the module on helping the low academic achievement students or the underachievers. Two groups (Control and Treatment) of Engineering Foundation Program students (mentee) in University Tenaga Nasional (UNITEN) consists of 40 people; 20 for each group with Cumulative Grade Point Average (CGPA) $<2.00$ points has been tutored by 40 trained mentors; 20 for each group, using established Peer Guidance Module (Control Group) and Peer Mentoring Module (Treatment Group) for 10 sessions/weeks. The mentees went through tutoring sessions for repeated subject; Calculus 1 (MATF 115) during their Trimester 2 2012/2013 session. Towards the end of the trimester, results for Calculus 1 will be analyzed on grade performance of both groups.

\section{Findings}

A pretest-posttest control research design was utilized to look at the difference of grade performance for Calculus 1 (MATF 115) for both groups; Control and Treatment group of the students (mentees) with low achievement (CGPA below 2.00 points). The Engineering Foundation Program students were categorized specifically by their major namely: 25\% Electrical Electronic (AE), 30\% Mechanical (AM), 20\% Power (AP) and 25\% Civil (AS) as in Figure 2 for Engineering Foundation Program and Figure 3 for distribution of gender. 
Figure 2: Frequency distribution of Engineering Foundation Program for Control and Treatment Groups

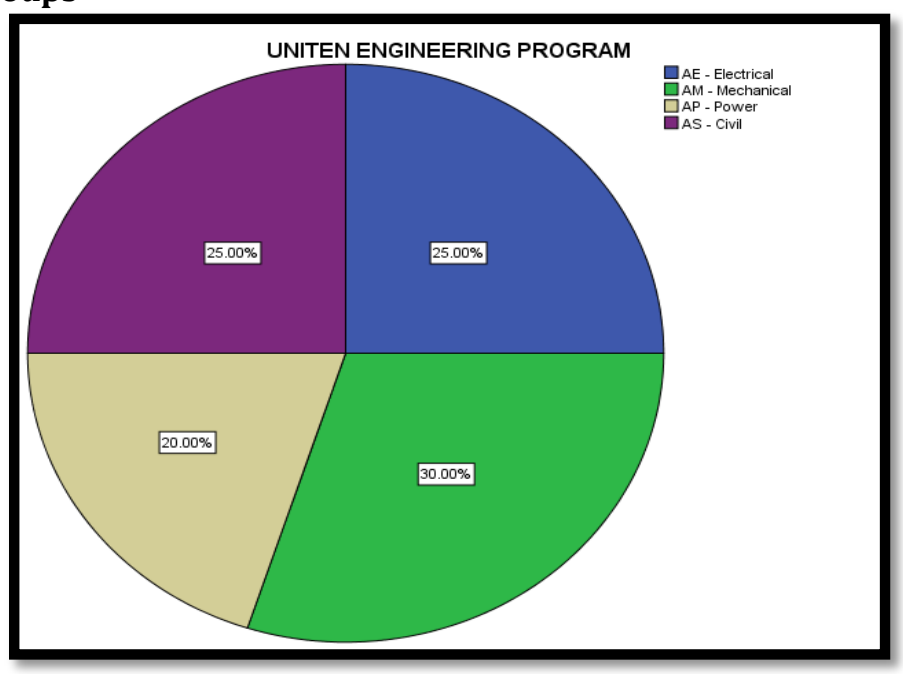

Figure 3: Distribution of gender for each group.

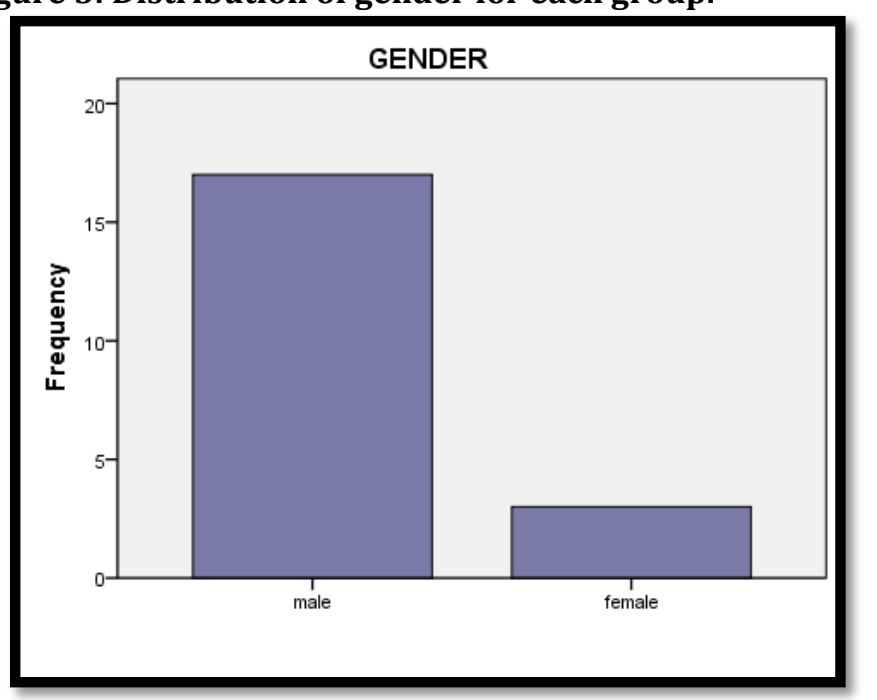

The results for grade performance of Calculus 1 obtained from the preliminary analysis of the frequency distribution are shown in Table 1. Levene's Test on homogeneity of variance showed no level of significance through data analysis of grade performance pre-test for Calculus 1 where there is no assuming violation on variance. This is because all respondents (mentees) failed their Calculus 1 for the first time (during Trimester 1). Whereas, Levene's Test on homogeneity of variance showed level of significance more than $.05(\mathrm{p}>.05)$ of grade performance post-test for Calculus 1 where there is assuming violation on variance. However, through nonparametric test, $p=.032(\mathrm{p}<.05)$, by using OneSample Kolmogorov Smirnov test; researcher concluded that there is significance effect statistically for grade performance post-test on Calculus 1 . Further to that, it shows that all respondents have passed Calculus 1 final exam for the second time during Trimester 2 ( $>40$ marks) on the repeated subject. As shown in Table 1, 40 respondents; 20 mentees for each Control group (Peer Guidance Module) and Treatment group (Peer Mentoring Module). Mean outcome showed that grade performance pre-test on Calculus 1 for both groups mentors and protégés in Academic Mentoring Program ( $M=39.00, S D=.000)$. Whereas, mean outcome for grade performance on Calculus 1 for post-test showed that for Control group $(\mathrm{M}=62.2500, \mathrm{SD}=9.6348)$ and Treatment group $(\mathrm{M}=54.5500, \mathrm{SD}=8.1336)$. 
Table 1: Descriptive Statistic on Pre-Test and Post-Test towards Grade Performance for Calculus 1

\begin{tabular}{|c|c|c|c|c|c|c|}
\hline \multirow{3}{*}{$\begin{array}{l}\text { Variables } \\
\text { Pre-Test } \\
\text { Calculus } 1\end{array}$} & Group & $\mathbf{N}$ & Mean & Std. Deviation & \multicolumn{2}{|c|}{$\begin{array}{l}\text { Homogeneity of Variances } \\
\text { df1 df2 Sig }\end{array}$} \\
\hline & \multicolumn{2}{|c|}{ Treatment 20} & 39.0000 & .0000 & \multirow[t]{3}{*}{2} & \multirow[t]{3}{*}{.$\quad}$. \\
\hline & Control & 20 & 39.0000 & .0000 & & \\
\hline & Total & 40 & 39.0000 & .0000 & & \\
\hline Post-Test & Treatment & 20 & 54.5500 & 8.1336 & \multirow[t]{3}{*}{2} & \multirow[t]{3}{*}{57.150} \\
\hline \multirow[t]{2}{*}{ Calculus 1} & Control & 20 & 62.2500 & 9.6348 & & \\
\hline & Total & 40 & 57.4500 & 9.9463 & & \\
\hline
\end{tabular}

Note: * The mean difference is significant at the .05 level.

In addition, the findings on impact strength subject within-group towards grade performance post-test on Calculus $1 \mathrm{~F}(2,37)=3.891, \mathrm{p}<.05$, eta square $=.120$. Because of $\mathrm{p}$ value is less than .05 , then the main effect for the group is statistically significance. Eta square value is .120, which indicates a major impact that shows from variability in grade performance for Calculus 1 relates with the intervention group. Table 2 shows the statistical finding on grade performance for Calculus 1.

Table 2: Statistical Findings on Grade Performance for Calculus 1

\begin{tabular}{llllll}
\hline Variables & Statistic & Df & F & Sig. Eta Sq \\
& & & & & \\
\hline Pre-Test & Between Group & 2 &. &. & - \\
Calculus 1 & Within Group & 37 & & & \\
& Total & 39 & & & \\
& & & & & \\
Post-Test & Between Group & 2 & 3.891 & .026 & .120 \\
Calculus 1 & Within Group & 37 & & & \\
& Total & 39 & & & \\
\hline
\end{tabular}

\section{Conclusion}

The overall findings support the objective that Peer Mentoring Module (PMM) intervention to train peer mentors in academic mentoring program shows positive effects on increasing the passing percentage of grade performance for Calculus 1 in Trimester 2 2012/2013. After 10 weeks during the post-test, there was statistically improved in Calculus 1 scores $(p<0.05)$, using nonparametric test. The findings clearly stated that passing level of Calculus 1 has increased 100\% with passing marks more than 40 marks. Mean outcome for Calculus 1 is 54.55 of the protégé (mentees) or the underachievers which has increased tremendously. The results suggest that the Peer Mentoring Module (PMM) would be best practised on every trimester for foundation program. Hence, with good academic achievement and best attitude, the Engineering Foundation Program students especially the underachievers will be well prepared to start their degree in Engineering Program. The research outcome may help researchers to proof that PMM through academic mentoring program can increase the attitude and confidence of the mentees. Therefore, a more positive learning perspective among the low achievers will be one of the important aspects in implementing the guidance group practice in the academic mentoring.

\section{References}

Anderson, E. M. \& Shannon, A. L. (1988). Toward a conceptualization of mentoring. J Teacher Educ, 39(1), 38-42.

Rogers, C. R. (1959). A theory of therapy, personality, and interpersonal relationships. In S. Koch (ed.), Psychology: A Study of a Science, vol. III. New York: McGraw Hill, 1959, 184-256.

DuBois, D. L. \& Karcher, M. J. (2005). Handbook of Youth Mentoring. Sage Publication, Inc. California, USA.

Haizan, M. T. \& Fauziah, H. A. J. (2012). Validity of Peer Mentoring Module in Mentoring Program with Underachievers. Conference proceedings at International Conference UPSI-UPI, Concorde Hotel, Shah Alam, Selangor. 
Haizan, M. T. \& Fauziah, H. A. J. (2012). The Effectiveness of Mentoring Through Peer Mentor Module Towards Cumulative Grade Point Average and Self Esteem of the Underachievers. Conference proceedings at National Research \& Innovation Conference For Graduate Students in Social Sciences'12, Mahkota Hotel, Melaka.

Oliver, P. J. \& Sanjay, S. (1999). The big five trait taxonomy: History, measurement and theoretical perspectives. In: Pervin LA, John OP, eds. Handbook of personality: Theory and research, 2nd Ed. New York: Guilford.

Wolf, D. M. \& Kolb, D. A. (1984). Career Development, Personal Growth and Experiential Learning, in Organisational Psychology. Prentice-Hall, New Jersey. 